\title{
Indian Nursing Council - It's role in evolving and administering paramedical professional ethics
}

\author{
S. P. Subashini \\ Principal, Santosh Nursing College, Ghaziabad, Uttar Pradesh, India \\ *Corresponding Author: \\ Email: subashini2976@gmail.com
}

\begin{abstract}
Introduction: Health care and health related services occupy a prominent place in human activities. Many of the health care centers do not follow the ethical practices due to lack of awareness.

Aim: The main aim is to assess the knowledge on nursing professional code of ethics in practice among nurse educators, final year nursing students and nurse clinicians and on the role of Indian Nursing Council in evolving and administrating the paramedical professional ethics.

Materials and Methods: Observational cross sectional study design with a total of 1200 respondents were assessed from college of nursing, school of nursing and their affiliated hospital in various districts around Tamil Nadu.

Results: The level of knowledge assessment on the nursing professional ethical codes among nurse educators reveals $63.0 \%$ adequate knowledge, among final year nursing students, $13.3 \%$ adequate knowledge and among nurse clinicians $7.0 \%$ adequate knowledge.

Conclusion: This study concludes that awareness on ethical codes in nursing curriculum and providing continuing education will optimize the high quality nursing care, as nursing profession faces legal issues and challenges.
\end{abstract}

Keywords: Indian Nursing Council, Knowledge, Nursing profession, Professional ethics, Code of ethics, Ethical principles.

\section{Introduction}

Health care and health related services occupy a prominent place in human activities. Many of the health care centers do not follow the ethical practices due to lack of awareness. Florence nightingale, the founder of modern nursing was the first one who in mid- $18^{\text {th }}$ century started quality nursing cares by introducing standards in nursing profession. Code of ethics and profession conduct along with practice standards provide a frame work for nursing in India.

Nurses perform different tasks in their profession including taking care of patients, decision making and to act as patients' confidents. Hence it is important for the nurses to be aware of their professional ethics as well as the moral principles of their job. Professional ethics in nursing are codes of conduct that are quite different from the norms of behaviors.

A study was conducted among 60 staff nurses to assess the knowledge and the practice of nursing ethics and laws in Nepal reveals that only $45 \%$ had adequate knowledge and the rest of them had inadequate knowledge on ethics and laws (Shrestha S. and Jose P. 2014). ${ }^{1}$

A study was conducted to assess the knowledge and practice of trained nurses in protecting the rights of the patients at Kochi in Kerala, India. The study revealed that more than half of the nurse population $(65 \%)$ has moderate level of knowledge while only one third of them have high level of knowledge about patients' rights (Rajesh Kumar et.al. 2011). ${ }^{2}$

\section{Materials and Methods}

An observational cross sectional study was conducted to assess the level of nursing professional ethical knowledge among the nurse educators, final year nursing students and nurse clinicians in Tamil Nadu, India. The researcher has identified ten districts in Tamil Nadu which have the minimum five nursing colleges and three nursing schools recognized by the Indian Nursing Council, New Delhi, and approved by the Tamil Nadu nurses and Midwives Council, Chennai.

From the Tamil Nadu Nurses and Midwives Council website recognized Nursing Colleges and Nursing Schools were selected through randomly from 10 districts and from each district the researcher has chosen 2 nursing colleges and 2 Nursing schools totaling 40 institutions and their affiliated hospital. 200 nurse educators, 200 final year nursing students, 200 nurse clinicians from each college and 200 nurse educators, 200 final year nursing students, 200 nurse clinicians from each school were selected (From each institution 10 nurse educators, 10 final year nursing students and 10 nurse clinicians were included in the sample case) with the total of 1200 respondents with multi- stage sampling method.

The knowledge domains used in the study were ethical principles, role of Indian Nursing Council, code of ethics and professional conduct, code of ethics for nurses and code of professional conduct for nurses respectively among nurse educators, final year nursing students and nurse clinicians.

A well-structured questionnaire schedule was drafted with demographic variables and assessment of 
knowledge on professional ethics and role of Indian Nursing Council among nurse educators, final year nursing students and nurse clinicians. The questionnaire were distributed and filled up by the respondents were collected by the researcher and the data were analyzed using $\mathrm{R}$ software version 3.3.0. Both descriptive and inferential statistics were used to interpret the data. Frequency and percentage distributions were used to analyze the socio-demographic variables and ' $t$ ' test were used to compare the professional ethics among the nurse educators, final year nursing students and nurse clinicians. One way ANOVA were used for association of knowledge with demographic variables. 'p' value < 0.05 were taken as the criteria of the significance.

\section{Results}

Table 1: Frequency and percentage distribution of the level of knowledge regarding professional ethics and the role of Indian Nursing Council among nurse educators, final year nursing students and nurse clinicians. $(\mathbf{N}=\mathbf{1 2 0 0})$

\begin{tabular}{|l|c|c|c|c|}
\hline Level of knowledge & Nurse educator & $\begin{array}{c}\text { Final year nursing } \\
\text { students }\end{array}$ & $\begin{array}{c}\text { Nurse } \\
\text { clinicians }\end{array}$ & Total \\
\hline Adequate $(>75 \%)$ & 252 & 53 & 28 & 333 \\
\hline Moderate $(51-74 \%)$ & 139 & 308 & 239 & 686 \\
\hline Inadequate $(<50 \%)$ & 9 & 39 & 133 & 181 \\
\hline Total & 400 & 400 & 400 & 1200 \\
\hline
\end{tabular}

With regard to the assessment of the level of knowledge on professional ethics and on the role of Indian Nursing Council among nurse educators final year nursing students, it is found that majority of the

respondents $(57.12 \%)$ have moderate knowledge on the knowledge domain and 333 respondents $(27.75 \%)$ have adequate knowledge and above $15 \%$ of the respondents have inadequate knowledge on domain parameters.

Table 2: Multiple comparisons of means: Turkey contrasts. $N=1200$

\begin{tabular}{|l|c|c|c|c|c|c|}
\hline \multirow{2}{*}{ Designation } & \multirow{2}{*}{ Estimate } & \multirow{2}{*}{ Std. Error } & \multirow{2}{*}{ t- value } & \multirow{2}{*}{ p- value } & \multicolumn{2}{|c|}{ 95\% confidence interval } \\
\cline { 5 - 7 } & & & & Lower Bound & Upper Bound \\
\hline $\mathrm{c}-\mathrm{a}==0$ & -14.8025 & 0.4792 & -30.89 & $<0.001$ & -15.9271 & -13.6779 \\
\hline $\mathrm{b}-\mathrm{a}==0$ & -8.2375 & 0.4792 & -17.19 & $<0.001$ & -9.3621 & -7.1129 \\
\hline $\mathrm{b}-\mathrm{c}==0$ & 6.5650 & 0.4792 & 13.70 & $<0.001$ & 5.4404 & 7.6896 \\
\hline
\end{tabular}

$\mathrm{a}=$ Nurse Educator, $\mathrm{b}=$ Final Year Nursing Students, $\mathrm{c}=$ Nurse Clinicians

With respect to the multiple comparisons of means (turkey contrasts) nurse clinicians verses nurse educators is highly significant where $p<0.001$ final year nursing students versus nurse educators is highly significant where $\mathrm{p}<0.001$ and final year nursing students versus nurse clinicians is highly significant where $\mathrm{p}<0.001$.

\section{Discussion}

The analysis of the socio- demographic variables of the 1200 respondents were analyzed, level of knowledge on professional ethics and role of Indian Nursing Council among nurse educators, final year nursing students and nurse clinicians were assessed, comparison within groups and between groups with ANOVA was done.
A descriptive study was conducted to determine the correlation between the nurse's perception of ethical climate and job satisfaction among the nurses in the teaching hospital in Iran. They studied 275 nurses working in 4 hospitals affiliated with the Kerman University of Medical Sciences. The data analysis was carried out using Pearson's Correlation, one way ANOVA, t-test and descriptive statistics through statistical package for social science version 16. The results reveal that there is a positive correlation among ethical climate such as type of professionalism $(\mathrm{p}=0.001)$, rules $(\mathrm{p}=0.045)$, caring $\quad(\mathrm{p}=0.000)$, Independence $(p=0.000)$ with job satisfaction. It was concluded that the managers of the hospitals can promote Nurse's job satisfaction by providing ethical training programmes that establish a working team and a culture that strengthens (Farida Borhani et. al. 2012). ${ }^{3}$ 
A descriptive study was conducted among the nursing students and nurse educators to analyze the ethical principles and issues relating to the work of nurse educators from the perspectives of both nurse educators themselves and nursing students in Finland. 202 nursing students and 342 nurse educators were under study and the results reveal that nurse educators and nursing students differ in their view based on three ethical principles such as professionalism, Justice and equality for nursing students and justice, equality and honesty for nurse educators based on the ethical issues arising in the work (Salminen L. et.al. 2016). ${ }^{4}$

In the present study, an attempt is made to assess the level of knowledge on nurse educators, final year nursing students and nurse clinicians on the nursing professional ethical codes. With regard to the assessment level of knowledge on the nursing professional ethical codes among the nurse educators, it is observed that $63.0 \%$ have adequate knowledge, $34.7 \%$ have moderate knowledge and $2.3 \%$ have inadequate knowledge.

A study was conducted to assess the performance of the nurses and their knowledge on nursing ethical codes from the nurses and patient's perspectives. 345 nurses and 500 in-patients from six teaching hospitals of Tabriz, Iran were selected. The results revealed that $86.4 \%$ of them were aware of ethical codes and $91.9 \%$ of the nurses and $41.8 \%$ of the patients stated that nurses respect ethical codes. A significant relationship was found between nurse's knowledge on ethical codes and job satisfaction. It was concluded that integrating ethical codes in nursing curriculum and providing continuous education will optimize nursing care (Mohajjel-Aghdam A. et. al. 2013). ${ }^{5}$

Further the assess the level of knowledge on the nursing professional ethical codes among the final year nursing students, it is found that $13.3 \%$ have adequate knowledge, $77 \%$ have moderate knowledge and 9.7\% have inadequate knowledge.

With regard to the assessment level of knowledge on the nursing professional ethical codes among the nurse clinicians, it is observed that $7.0 \%$ have adequate knowledge, $59.7 \%$ have moderate knowledge and $33.3 \%$ have inadequate knowledge.

Data were also collected on the scores gained by the respondents related to their different domains of knowledge. With regard to the nurse educators, $51.7 \%$ scored on ethical principles, $71.7 \%$ scored on role of Indian Nursing Council, 52.2\% scored on code of ethics and professional conduct, $50.7 \%$ scored on code of ethics for nurses in India and $65.5 \%$ scored code of professional conduct for nurses in India, overall 63\% demonstrated adequate knowledge.

With regard to the final year nursing students on the different domains under study, $10 \%$ scored on ethical principles, 37\% scored on role of Indian Nursing Council, 35\% scored on code of ethics and professional conduct, $31.3 \%$ scored on code of ethics for nurses in
India and 35\% scored code of professional conduct for nurses in India. Overall $13.3 \%$ demonstrated adequate knowledge.

A cross-sectional study was conducted among nurses to determine their knowledge in ethics and their perception about Continuous Ethics Education for the Nurses (CNEE) in Uganda.114 Nurses from three hospitals were studied and the results revealed that $16 \%$ of the respondents scored $>50 \%$ in the test on ethical knowledge and only $45 \%$ of nurses had attended one Continuous Ethics Education (CNEE) session and up to 93\% agreed that this programme is required for improving the nurses' ethics knowledge and practice. Hence CNEE programme should be given to the nurses to increase the ethics knowledge and competencies among the nurses. (Charls Peter Osingada et. al. 2015). ${ }^{6}$

With regard to the nurse clinicians on the different domains under study, $6 \%$ scored on ethical principles, $18.8 \%$ scored on role of Indian Nursing Council, 11.7\% scored on code of ethics and professional conduct, $7.5 \%$ scored on code of ethics for nurses in India and 14.4\% scored code of professional conduct for nurses in India. Overall 7\% demonstrated adequate knowledge.

\section{Conclusion}

The nursing profession is of high ethical values and the health care professionals have ethical commitments and responsibilities for self-regulating professionalism. The role of Indian Nursing Council formulates syllabus and releases professional code of ethics book, which revitalizes and nurtures the nursing professionals. Hence integrating nursing curriculum and providing continuing education on nursing professional codes will optimize the high quality nursing care. So nurse practitioners will be accountable and responsible in relation to ethical and legal issues. Ethical theories and principles provide the evidence base to support decision making.

\section{References}

1. Shrestha $\mathrm{S}$ and Jose P. Knowledge and Practice of Nursing Ethics and Laws. J Uni Col Med Sci 2014;2(3):30-3.

2. Rajesh Kumar, Santosh Mehta, Raminder Kalra. Knowledge of staff Nurses regarding legal and ethical responsibilities in the field of psychiatric nursing, Nurs Midwi Res J 2011;7(10):1-11.

3. Farida Borhani, Tayebeh Jalali, Abbas Abbaszadeh, Ali Akbar Haghdoost and Mohammadreza Amiresmaili. Nurses perception of Ethical Climate and Job Satisfaction. J Med Ethics Hist Med 2012;5(6):1-6.

4. Salminen L, Stolt M, Metsamaki R, Rinne J, Kasen A, Leino-Kilpi H. Ethical Principles in the work of nurse educator- A cross-sectional study. Nur Edu Tod 2016;36:18-22.

5. Mohajjel Aghdam A, Hassankhani H, Zamanzadeh V, Khamenneh S, Moghaddam S. Knowledge and Performance about Nursing Ethic Codes from Nurses' and Patients Perspective in Tabriz Teaching Hospitals, Iran. J Caring Sci 2013;2(3):219-27. 
6. Charls Peter Osingada, Gorrette Nalwadda, Tom Ngabirano, John Wakida, Nelson Sewankambo, and Damalie Nanjako. Nurses knowledge in Ethics and their perceptions regarding continuing ethics education: A cross-sectional survey among nurses at three referral hospitals in Uganda. BMC Res Notes 2015;8(319):1-5. Available from

https://bmcresnotes.biomedcentral.com/track/pdf/10.1186 /s13104-015-1294-6. 